\title{
Developed Automated Electoral System Algorithm using Biometric Data to Eliminate Electoral Irregularities in Nigeria
}

\author{
R.E Okonigene \\ Department of Electrical and Electronics \\ Engineering, Ambrose Alli University, P.M.B. \\ 14, Ekpoma.
}

\begin{abstract}
This paper presents an aspect of research work that was carried out to resolve the many challenges in Nigeria electoral process. All efforts by Nigerian voters to ensure that their votes are counted and used to declare results in all the general elections conducted failed. The officials saddled with the responsibilities to conduct and declare election results in Nigeria, connived with dubious Politicians, thugs, and members of the Nigerian Police to rob eligible voters of their votes. Hence, all the elections in Nigeria have been marred with the worst form of electoral irregularities. To give credibility to elections in Nigeria therefore we proposed an automated electoral system that use biometric data to conduct all elections in order to protect and present accurate election results that truly represents 'one person one vote'. This research work accurately identified and removed all duplicate registrations in the voter's database. Equally we had an automated 'one person one vote' election results by using Netcracker suite to simulate the automated election process for a network of 120,001 polling units, 8812 wards ,774 Local Government Areas, 36 States, and 6 Geo-Political areas and Abuja. We noted the Bandwidth, throughput, latency, bottleneck, and congestion challenges. The simulation and the associated results are not included in this paper. This automated electoral system was designed in accordance with Nigeria electoral laws and topographical data. We estimated that 370,000 ad hoc staff is needed to successfully implement and use this system, on Election Day, to conduct a free and fair election. Out of these numbers of staff 190,000 would be fully employed for the use of this equipment during and after the elections. The project cost estimate was USD $\$ 390,000,000$. Our test results showed that the system can be physically and successfully implemented in Nigeria.
\end{abstract}

\section{Keywords}

Automated Electoral System, Developed Electoral Algorithm, Biometric Data, Electoral Irregularities, Nigeria INEC

\section{INTRODUCTION}

All the National elections, which included the Presidential, the Governorship, the National and the State assemblies that have been conducted since November 1965 to April 2007, in Nigeria, were marred with violence and election irregularities [1]. There were extensive protests at the apparent perversion of the democratic process, which led to the death of an estimated 2000 people in the violence that erupted in the Western Region in May 1966. The 1979

\author{
C.E Ojieabu \\ Department of Electrical and Electronics \\ Engineering, Ambrose Alli University, P.M.B. \\ 14, Ekpoma.
}

presidential election, 1983, 1999, April/May 2003 and 14 April 2007 general elections witness violence and virtually all election results were contested in court [2]. Politicians across Nigeria acquire or retained political support, wealth and influence through the use of all manners of electoral violence and irregularities. Nigerians were intimidated by violence aimed at silencing their voices. Killing, rioting, and stealing of ballot papers and boxes and destruction of properties were eminent $[4,5,6,7,8]$. A number of the electoral verdicts were rescinded in view of evidence that results were falsified. The 1992 elections results were annulled by the military government of General Ibrahim Babangida claiming electoral fraud. Again the election results of June 1993 were again annulled on June 12, 1993 thereby denying the acclaimed winner Chief Moshood Abiola the people's mandate. Babangida again claimed electoral fraud as the reason for the annulment of the results of the election. In some parts of the country due to the nature of the terrain, such as the Riviera in the South, it was difficult for INEC to carry electoral materials to these areas. To put an end to these problems of election malpractices, irregularities and violence in Nigeria, we proposed an automated electoral system that incorporated the complete use of Biometric data of all Nigeria citizens and this included those in Diaspora to conduct all elections in Nigeria. This system is different from commercially available electronics voting systems. The implementation in Nigeria is feasible. If implemented Nigeria will be the first most populated African country to have a biometric database of all its citizenries and to implement an automated electoral process using biometric data in the world.

\section{MATERIALS AND METHODS}

There is currently no biometric data base of all Nigerians. Biometrics can be used to identify the citizens, having all their data stored in a large database. For Nigeria, one of the most densely populated countries in the world, the creation of an accurate voter registration database has been a monumental task. Using biometric technology over 250 million people can be registered within one month and specifically for the purposes of elections. As a first major step, in this automated system, we acquired biometric data of the face, iris and 10 finger print to register voters. These data, from the database were subjected through a deduplicate process. Thus, we accurately identified and removed all duplicate registrations in the voter database. With such a large database, the search for duplicates was a complicated task that required a large number of matching operations and a high degree of reliability.

The second major step was the voting and counting process, where the automated system relied solely on the 
database server and the physical presence of the voter. All credible votes are counted and displayed at specified collation centers across Nigeria putting into consideration the secrecy of each vote.

\section{RESULTS AND DISCUSSION 3.1 Registration and Voters Information Capture Process}

In this process, information of legal potential voters are captured and stored in the Database Server as shown in Figure 1. This capturing of information was done from the different registration terminals, the client computers in different Voters Registration Centers throughout Nigeria including those in Diaspora. Captured information includes personal data, 10 fingerprint, facial scan, iris scan, after which a Voter's Slip/Card with a unique voter's identity number was printed out and given to the successfully registered voter.

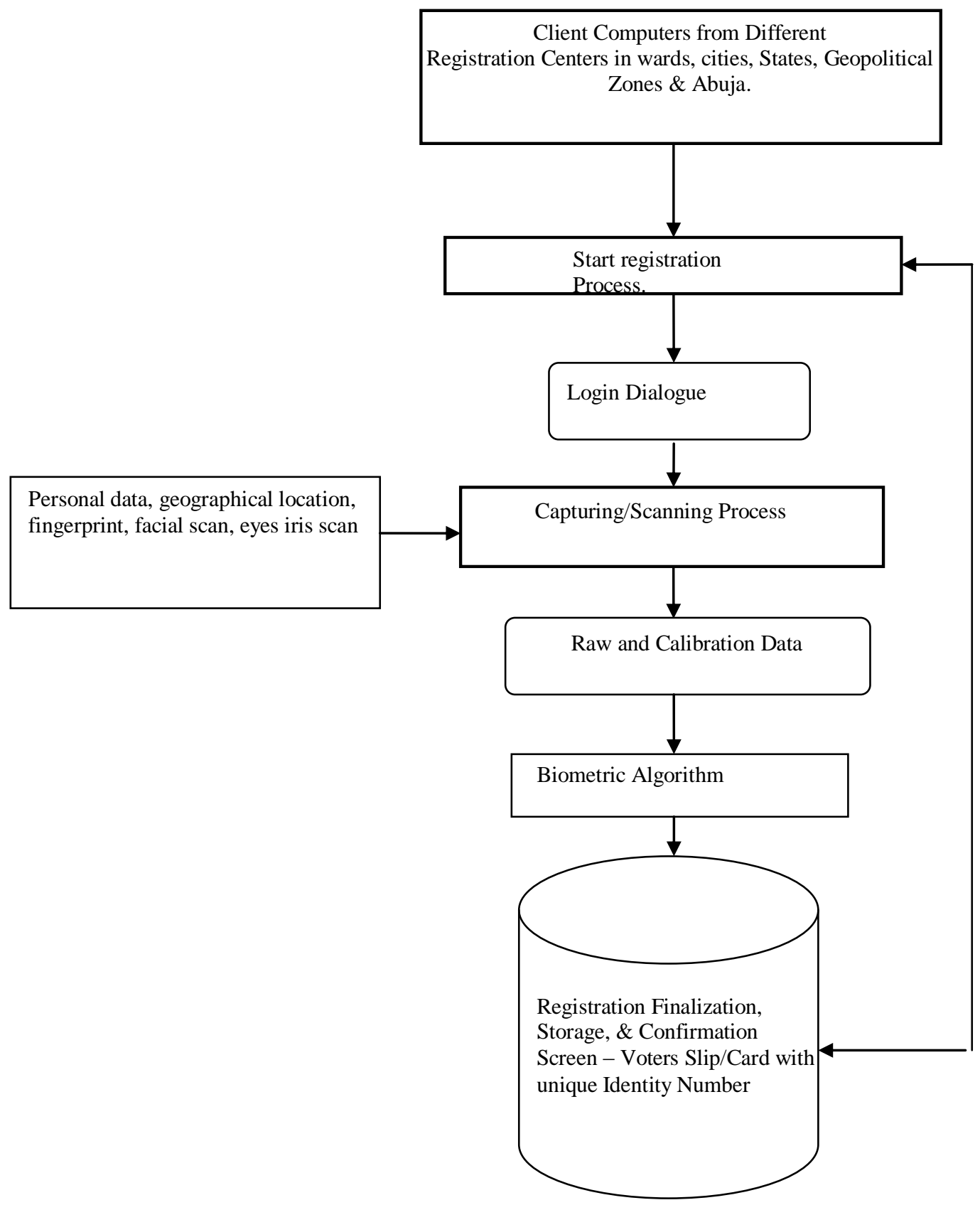

Figure 1 Registration of voters and data acquisition

\subsection{Voting process}

Voters in Nigeria and in Diaspora will visit any of the Registration/Voting centers and not necessarily where they registered. The system verifies, validates, or authenticates the information entered during the registration for each individual registered voter as shown in Figure 2. Successful verification of entered information leads to a successful vote. The verification process begins with the authentication of the Voter's Identity Number, then the Fingerprint, Face Recognition, and then Iris. Failure of any 
of these verifications for a specified number of times terminated the voting process, and the Database Server will take note of the failure. Taking note of verification failures was necessary to stop the voting process at the initial stage when the same "failed voter" tries to vote from another Client Computer in another location. This helped to avoid the need of making any further verification. The system was designed to be flexible enough and can work with a variety of input devices. For the purpose of this research work we used PC Cam Web cams for capturing face images and Digital Persona U.are.U 4500 fingerprint scanners to generate data for fingerprint templates. The simulated system stored the face and fingerprint images in a MySQL database in WSQ format.

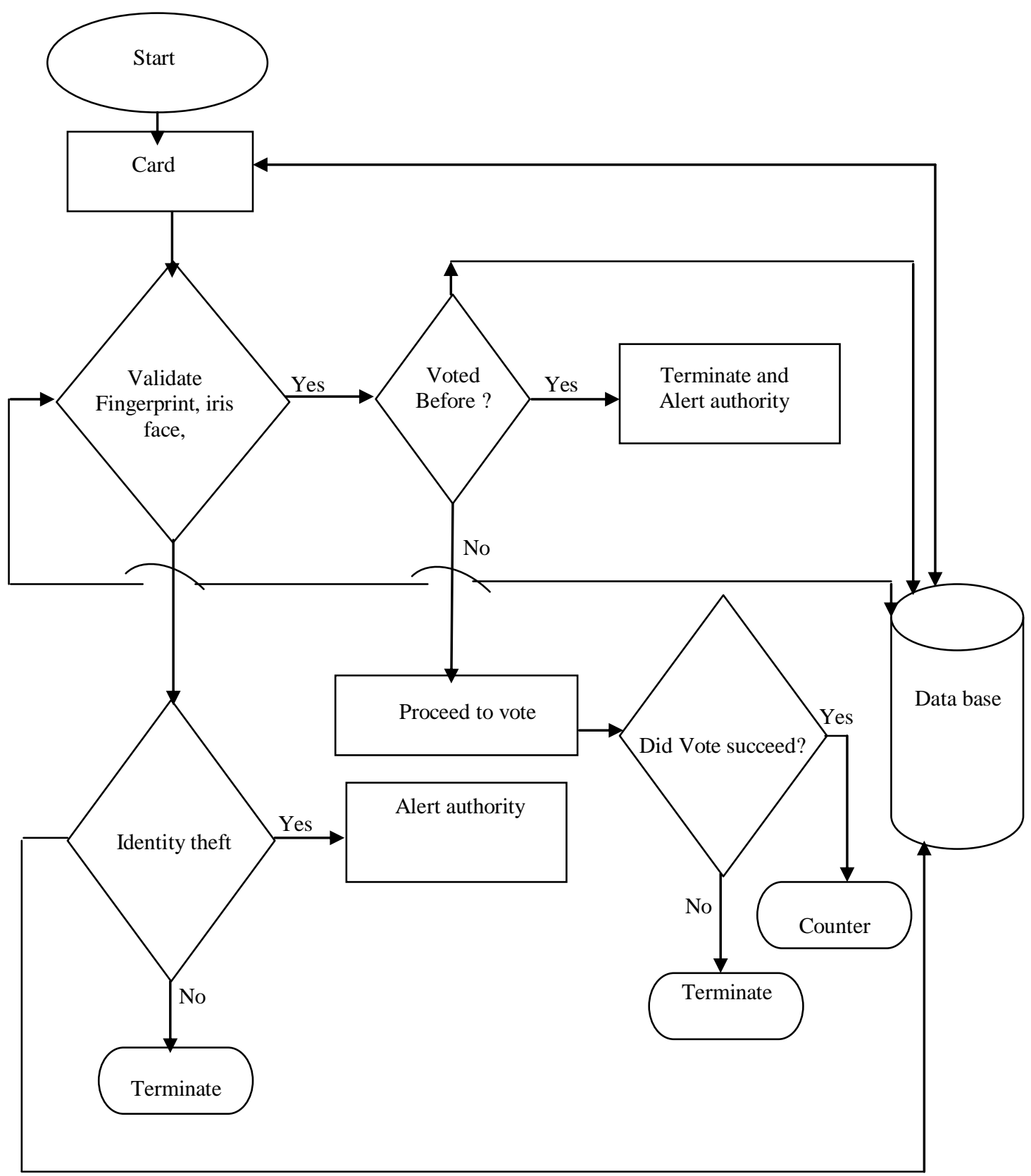

Figure 2. The voting flowchart

\subsection{Template generation}

The Template Generation Module, based on the system client, reads the WSQ images from the MySQL database and generates fused face and fingerprint templates that are then stored in a SQL Server Database. The system then uses these templates to carry out the biometric "N-to-N" matching process that identified duplicates within the database records. Matching algorithms were used to compare previously stored templates of a voter fingerprints, face, and iris for authentication purposes. In order to achieve our goal the original image was compared with the candidate image. The main database server was 
located in Abuja. Other servers are located in the 36 States capital and the 6 geopolitical zones where the client computers are linked and also connected through the internet. The super-speed lines were preferred because the Web Application has to be hosted on the local computer system where it was made available on a network through the Internet $[9,10]$.

\subsection{Client computers}

Client computers are computers stationed in the different Voting and Registration Centers in different States, LGAs and Wards in Nigeria, where they connect and interact with the Database Servers. The Client computer is different from the database server in the sense that it has no database installed, except the Web Application, which takes information and sends them to the Database Server. Whenever information needs to be retrieved, the Web Application in the Client computer queries the Database Server and information requested for was granted.

The system ran on Microsoft Windows 7. For biometric matching at the lowest level of administrative jurisdiction stand alone server was used. It had the capacity to match up to 500,000 records. Cluster Server provides significantly higher capacity depending on the number of Cluster Nodes used. For the voter's system, Cluster Server is configured to match up to 5 million records at a time. Table 1 shows some specifications of the server. Netcracker suite was used to simulate this automated system that comprises a network of 120,001 client computers (number of polling units or voting centers) that were linked to 8812 wards, 774 LGAs', 36 State capitals, 6 geopolitical zones and the Federal capital territory Abuja.

Table 1 Computer specifications

\begin{tabular}{|l|l|}
\hline $\begin{array}{l}\text { Cluster Server } \\
\text { Specification: }\end{array}$ & $\begin{array}{l}\text { Cluster Node } \\
\text { Specification: }\end{array}$ \\
\hline Processor: Intel Core Two & RAM: 4GB \\
Duo 2.97 GHz & Hard Disk: 500GB \\
RAM: 4GB & OS: Windows 7 \\
Hard Disk: 500GB & \\
OS: Windows 7 with & \\
Service Pack 2 & \\
Database: SQL Server 2000 & \\
\hline
\end{tabular}

\subsection{Advantages of this proposed system.}

1. Elimination of election irregularities, which include thug-gery and stealing of ballot boxes during election.

2. A situation where figures are assigned to results will be a thing of the past. It is simply 'one man one vote'.

3. Reduce election results dispute thus assuring the conduct of credible elections.

4. The system allows Nigeria in Diaspora to vote.

5. Every Nigeria can vote irrespective of where he or she registered or is resident.

6. Elimination of void vote.

7. Reduction in delay time of voting.

8. Timely disclosure of Election results is assured

9. Number of eligible registered voters and Nigerian population will be known.

10. Elimination of registration for the next elections.

11. The population in each Units, Wards, LGA, and States at any point in the future will be known.

12. The System helped to ensure the administration of free/fair and democratic elections by verifying the accuracy of the country's national voters' database.
13. The biometric algorithm can rapidly and accurately identify duplicate face and fingerprint records in the large database.

14 Fully automatic, robust, fault tolerant software manages a huge workload.

15 The system's low cost-per-unit and low hardware system requirements enable a cost-effective solution for a rapidly developing nation.

\section{CONCLUSION}

The implementation of this automated electoral system using biometric data would enable the hosting of free and fair election in Nigeria. This system will help to eliminate election irregularities, the stoppage of thug's activities at polling booths and the stealing of ballot boxes. This will also give credibility to elections in Nigeria. The citizen can be sure that they alone can choose their leaders, thus exercising their right in the democratic process. The results obtained from this research work showed that this automated electoral system will help to resolve the many ugly challenges in Nigeria electoral process.

\section{REFERENCES}

[1] University of Pennysylvania - Africa studies centre (2003) Nigeria: Political violence and elections Africa policy E-journal February 3.

[2] Dayo A. (2008). Waiting for judgment day. TELL 8, January 25:40-43

[3] Dayo A.(2008).We are guilty. TELL 14, April 7:27-31

[4] Olalenkan O., Adewale A., Tope A., and Rotimi O..(2007). Bloodbath in Lagos, Ibadan. Nigerian Tribune14133, April 11:1,4

[5] Lanre Adewole. (2007). Election must hold Saturday. Nigerian Tribune14133, April 11:1,4

[6] The Guardian reporters (2007).Large turn-out, bloodshed at polls. The Guardian 24, April 15:1,6

[7] Ogugbuja C.(2007). Confusion in Imo over ballot papers. The Guardian 24, April 15:7

[8] INEC. (2007). 50 killed, 1093 arrested during guber polls. The NIGERIAN OBSERVER 35, April 30:1

[9] N. K. Ratha, J. H. Connell, and R. M. Bolle,(2001) "Enhancing security and privacy in biometrics-based authentication systems," IBM systems Journal, vol. 40, pp. 614-634.

[10] A. Mascher-Kampfer, H. Stögner, A. Uhl. (2007) Comparison Of Compression Algorithms' Impact On Fingerprint And Face Recognition Accuracy. In Visual Communications and Image Processing 2007 (VCIP'07), Proceedings of SPIE 6508, p. 650810-1 650810-10 